\title{
EAMR
}

European Accounting and

Management Review

EUROPEAN ACCOUNTING AND MANAGEMENT REVIEW · VOL. 1, NO. 1, 25-43 NOVEMBER 2014

\section{An ISO 10002:2004-based feedback-handling system for the emergency and inpatients care}

\author{
Mohammad Ashiqur Rahman Khan \\ University of Alberta \\ Stanislav Karapetrovic \\ University of Alberta
}

Received April 30, 2014; accepted August 1, 2014.

\begin{abstract}
The development of an ISO 10002:2004-based system for handling unsolicited patient feedback within a continuum of care in a Canadian hospital is presented. Through interviews of registered nurses, unit managers and experts, patient encounters and existing feedback-handling activities were studied and the learning was incorporated in a Feedback Handling System (FHS). Guidance from ISO 10004:2012 was used in defining FHS maintenance activities. New activities and items that are not suggested in ISO 10002:2004 were introduced. The FHS follow-up component was validated through actual patient feedbacks. The usefulness and feasibility of the developed FHS were verified by interviewing research participants. According to the feedback-handling experts, the FHS could be useful at the unit-level. To our knowledge, this paper shows the first application of ISO 10002:2004 in integrated health care. It also demonstrates an example of the "augmentation" of ISO 10002:2004 with ISO 10004:2012-based monitoring of patient satisfaction in integrated health care.
\end{abstract}

\section{KEYWORDS}

Integrated health care, ISO 10002, ISO 10004, standards, patient centeredness, continuum of care. 


\section{Introduction}

Customer feedback provides a wealth of information about a customer's expectations and perceptions about the received product and service. Customers of health care include the public in general and the patient in specific (Deffenbaugh, 1994). Furthermore, the patient family and friends, also considered as health care customers (O'Malley et al., 2008), provide useful feedback. Numerous studies can be found on the importance of feedback in health care (e.g., Stichler and Schumacher, 2003; Seelos, 1994; Levine et al., 1997). Feedbacks are important not only for understanding the patient perception, but also for identifying the problem areas and improvement opportunities. Complaints are considered a useful indicator of service quality (Kline et al., 2008). ISO 10002:2004, a customer satisfaction standard, provides guidance for the design and implementation of a complaints-handling process. Surprisingly, studies on the application of ISO 10002:2004 in health care are still rare.

Unlike the traditional health care that is provider-centered and focused on systems rather than patients (NHS, 2003; Friedman et al., 2001), Integrated Health Care (IHC) is " $a$ coordinated organizational process that seeks to achieve seamless and continuous care, tailored to the patients' needs" (Mur-Veeman et al., 2003). IHC advocates providing patient-centered care with well-connected services (Suter et al., 2009; Ouwens et al., 2005; Thomas, 2007; Kerberet al., 2007; Lamb, 1997; Armitage et al., 2009). With its patient focus, integration may reduce fragmentations within the organization and improve continuity and coordination of the care (Ouwens et al., 2005; Rygh, 2007). It is possible that patient feedback can be obtained and used more effectively and efficiently in an IHC system than in a traditional system, in which the feedback-handling can be isolated and discontinuous. Surprisingly, no work on handling unsolicited patient feedback within the IHC setup can be found in the literature. Nonetheless, it is an interesting problem to explore because the benefits of IHC should also be realized in feedback handling.

In this paper, the application of ISO 10002:2004 in developing a Feedback-Handling System (FHS) for IHC is illustrated. A care continuum consisting of the Emergency Department (ED) and inpatients care in a Canadian hospital was assumed as an IHC case. First, the significance of handling feedback in IHC is discussed and the existing frameworks found in the literature are reported. Then, the existing activities within the care continuum are identified and analyzed based on interviews with the research participants, which includes care providers and feedback handling personnel. Subsequently, the development of an ISO10002:2004-based FHS is presented with the 
details of the operational and maintenance processes. The maintenance process is further augmented by using ISO 10004:2012, a standard for monitoring and measuring customer satisfaction. The feasibility, usefulness and potential implementation of the FHS are analyzed with inputs from the research participants. The follow-up activities are verified by investigating actual feedbacks that were documented in a developed form. Conclusions are drawn regarding the findings and future research directions are proposed.

\section{Feedback-handling: Significance and Frameworks}

Feedbacks are "the opinions, comments and expressions of interest" (ISO 10002:2004, sub-clause 3.6). Interestingly, the expression of dissatisfaction is firmer and more reliable than that of satisfaction (Coyle and Williams, 1999; Mulcahy and Tritter, 1998). Therefore, patient dissatisfaction can indicate systematic issues and uncover potential improvement opportunities regarding the care quality and patient experience (Davis et al., 2008). However, a very small number of dissatisfied customers actually convey their dissatisfaction (Stichler and Schumacher, 2003), but may convey their bad experience to others (Stichler and Schumacher, 2003; Kress and Silversin, 1983; Eccles and Durand, 1998; Gingold, 2011). The study of complaints helps in identifying problem areas that are causing patient dissatisfaction (Stichler and Schumacher, 2003; Saravanan et al., 2007; Anderson et al., 2000) and opportunities for quality improvement (Anderson et al., 2000). Moreover, feedback data can act as the indicator of customer expectations and satisfaction (ISO 10004:2012, Clause 1). Complaints are sometimes conveyed by a third party such as a relative (Anderson et al., 2000). However, patients may refrain from raising their concerns fearing negative consequences (NHS, 2003). Therefore, patients, as well as their family and friends, need the encouragement and assurance to leave feedbacks. Additionally, staff members can be assigned to monitor that the customer needs are fulfilled (Eccles and Durand, 1998). Building capacity for having a proper feedback-handling system and treating complaints as improvement opportunities are strongly recommended (Seelos and Adamson, 1994; Hsieh et al., 2000). An appropriate system for handling feedback would also be significant in IHC, which is known for its focus of the patients and the continuum of care.

In the literature, there are examples of complaints handling frameworks, as well as tools for the collection and analysis of feedback and its use (e.g., Zairi, 2000; Osborne, 2004; Nordlund and Edgren, 1999). Health care specific examples are discussed in Allen et al. 
(2000), Kress and Silversin (1983), HQCA (2007), NHS (2003), Smith and Swinehart (2001) and Hsieh et al. (2005). The only well-known international standard on complaints handling is ISO 10002:2004, which is a "guideline standard" that is not intended for certification. It includes guidance on the planning, designing, operation, maintenance and improvement of a complaints handling process. Applications of ISO 10002:2004 can be found in the literature in various areas, including an electrical utility (Hughes and Karapetrovic, 2006), fast-moving consumer goods (Ang and Buttle, 2012), university education (Karapetrovic, 2010; Honarkhah, 2010), health insurance (Ang and Buttle, 2012) and health care (Ang and Buttle, 2012; Fernandez et al.,2010; HQCA, 2007). To our knowledge, there has not been any research on standardized feedback-handling within IHC, and that provides the motivation for this research.

\section{Methodology}

This research was initiated as part of a project on customer satisfaction in IHC (Capital Health, 2008). Although the principles and components of IHC are identified and analyzed in the literature, "Patient centeredness" (O'Malley et al., 2008; Suter et al., 2009; Friedman et al., 2001) and "Comprehensive service across the continuum of care" (Suter et al., 2009; Friedman et al., 2001) are focused on in this paper because of their relevance to feedback-handling. The patient focus is engraved into the FHS by applying ISO 10002:2004 with its principles and guidance. An Emergency Department (ED) and inpatients care of a hospital was assumed as an example case of IHC. The experiences of patients who receive care in the ED and get admitted in the inpatients care were the focus of this research. The FHS was developedby considering this continuum of care as one system in an approach that is different from traditional feedback-handing at each stage of the continuum individually.

ISO 10002:2004 does not detail the validation of the feedbacks or the communication and reporting of the results from the feedback analysis. Therefore, in further defining these maintenance activities, ISO 10004:2012, was applied in addition to ISO 10002:2004. 
This research involved the following steps, which are detailed in the next section:
A. Study the care continuum;
B. Determine the existing feedback-handling activities;
C. Develop an FHS;
D. Verify the FHS's usefulness and feasibility.

As part of the first two steps, the hospital's internal documents and publicly available reports were studied and the research participants were interviewed. The research participants included one Program Manager (PM), three Unit Managers (UMs) and four Registered Nurses (RNs) from the ED and inpatients care, as well as two feedbackhandling experts. After the development of the FHS, its usefulness was verified by interviewing each group of participants. Based on the responses from one group, the FHS was modified and passed to the next group before their interviews. Additionally, the follow-up component of the FHS was tested through tracking actual patient feedbacks by one of the participants. The results are now discussed.

\section{Results}

\subsection{Study of the care continuum}

Based on the interviews with participants, flowcharts depicting the care processes within the continuum were constructed. For each activity within the care flow, the "SIPOC" elements, i.e., "Supplier-Input-Process-Output-Customer" (Miller, 2005), and the care provider(s) were determined. The intent was to focus on a patient's journey from the initiation to the end of the care, as well as to identify the "moments of truth" i.e., the service encounters during which a patient makes judgment on the quality of care (Osborne, 2004). Therefore, every patient encounter with the health care provider or organization can have the potential for feedback (Osborne, 2004). Because the higher the clinical complexity, the higher the likelihood that concerns may occur (Kline et al., 2008), patients who go through multiple procedures and stages are more likely to have feedback. For instance, the study of the care flowchart helped to identify two such points in the continuum for which there is a potential for concerns. They were: (1) patients waiting in the ED and (2) patients being handed-off from the ED to inpatients care. Patients wait for the next step of care at both these points and a long waiting time can initiate patient complaints. 


\subsection{Existing feedback-handling activities}

Based on the interviews of the participants, as well as the study of the available reports, the following conclusions were drawn:

- The ED and inpatients care patients may leave feedbacks with a feedbackhandling department within the province. This department conveys the received feedback to the related health care unit of a hospital and records the follow-up activities. However, neither the ED nor the inpatients care units in the hospital have their own system of feedback handling. The feedbacks received within the units are typically handled individually by the UMs and the care providers.

- No defined process exists in the hospital for the collection and follow-up of orallyconveyed feedbacks. However, in the Canadian province of Alberta, where the hospital is located, a large number of patients with serious complaints complain orally (HQCA, 2010).

- Within the ED and inpatients care units, there are no defined feedback monitoring or feedback-based improvement activities.

- Feedback follow-up activities may not be tracked effectively and consistently when the feedback involves personnel such as physicians, therapists, social workers and dietary staff, who are outside of the chain of command of the ED and inpatients care.

- Issues may happen at the handing-off: a feedback received in the ED may not be communicated to the inpatients care even though the patient is handed off to the inpatients care.

- The UMs of ED and inpatients care are responsible for their own units' feedback follow-up activities. However, no defined process exists for helping the coordination among the UMs in their handling of feedbacks.

While the first three are gaps in the existing system, the remaining are continuum issues that should be addressed in an integrated system. Consistent with the idea of a providercentered health care system, which typically cannot offer a complete view of a patient's care experience along the entire care continuum (Lamb, 1997), the existing feedbackhandling activities are discontinuous and isolated. Therefore, a unit-level FHS along the care continuum should be useful and efficient in addressing both the continuum issues and the identified gaps. The following sub-sections illustrate the development and a partial validation of the FHS. 


\subsection{Development of the FHS}

Guidance from ISO 10002:2004 was used in developing an FHS, with the focus on the unit-level handling of feedback. Complaints and recommendations were both considered as inputs. Hence, the scope of ISO 10002:2004, which is specific to complaints only, is augmented. The FHS components, which are illustrated below, include a policy (based on sub-clause 5.2, ISO 10002:2004), objectives (6.2), responsibility and authority of the personnel (5.3), operational process (7) and maintenance and improvement process (8). The latter process was further enhanced by applying guidance from ISO 10004:2012.

\subsubsection{The FHS Policy}

During the time of the research, the hospital did not have a specified feedback-handling policy. The intent of the half-page policy developed as part of the FHS was to build a culture of listening to the voice of patients and enhancing satisfaction. The policy was developed and worded based on the ISO 10002:2004 guiding principles in Clause 4. The policy included statements on the "visibility", "accessibility", "responsiveness", “objectivity", “confidentiality", “customer-focused approach", “accountability" and "continual improvement" of the FHS. "Charges" was the only principle not included, because there is no money is involved in the process of patients leaving feedback. As an example of how the FHS policy reflects the ISO 10002:2004 principles, the policy states: "The patient focus is emphasized by encouraging and facilitating the collection and follow-up of patient feedback, sincerely committing to resolving issues, implementing corrective, preventive and improvement actions, and replicating the good practices and recommendations".

Interestingly, patient focus (“Customer Focus", as illustrated in sub-clause 4.8) is also a core principle of IHC. "Responsiveness" and "accountability" pertaining to the FHS are relevant to the continuum of care, both being improved by the integrated and collaborative handling of feedbacks by the personnel involved in multiple stages of the care.

\subsubsection{The FHS objective}

The core objectives of the FHS are to obtain feedbacks by involving the care providers closest to the patients in resolving concerns within the care continuum and to use the results from the feedback analysis in improving the care. Additionally, the FHS should help in providing a snapshot of patient satisfaction regarding the care received. By involving care providers, quicker resolution of complaints should be achieved. These 
objectives are connected with the IHC principles (i.e., patient centeredness and the continuum of care), are consistent with the policy, and are measureable through the suggested indicators (discussed in sub-section 4.3.5 below).

\subsubsection{Responsibility and authority}

The UMs from ED and inpatients care are responsible for leading and managing the feedback tracking activities. For a different setup, this responsibility can be assigned to other personnel as necessary. Thus, "accountability" is established, which is a principle of ISO 10002:2004 (sub-clause 4.9). Communication and collaboration between the UMs of the two stages should help making the feedback-handling "seamless" and "coordinated" (Mur-Veeman et al., 2003) along the continuum, which are the attributes of IHC that distinguish it from the traditional care.

\subsubsection{Operation of the FHS}

The UM and nurses can inform the patients of the ways to leave feedback, including a feedback form designed to obtain written feedbacks from patients and the locations of the feedback drop boxes, as well as of the manner in which the feedbacks would be used (ISO 10002, sub-clause 7.1). The UM can check the drop boxes every day for feedbacks left by patients, or assign the duty to an assistant, such as the Unit Clerk. The locations of the drop boxes are determined following the study of the care continuum (see step 1 of the methodology). For the ED, the drop box should be placed in the waiting room and for the inpatients care, the locations chosen were next to the reception desk, inside a ward and on the wall of the corridor within the unit (Figure 1). In all three locations, patients may have to wait or are between procedures, which allow them opportunities to fill-out the feedback form.

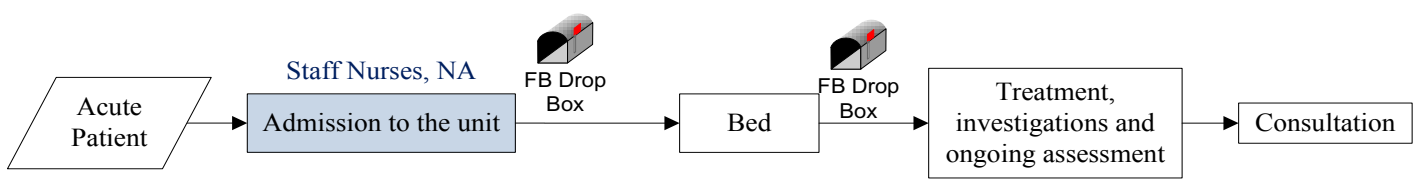

Figure 1. Inpatients unit locations of the feedback drop boxes

Figure 2 illustrates the FHS's operation, including the ISO 10002:2004 sub-clauses in parenthesis. Patients can leave feedback by informing the care provider (e.g., doctors and nurses), by filling the feedback form and dropping it into the feedback drop boxes, through emails, letters and phone calls, as well as by contacting external parties, such as 
the central feedback-handling department and the media. Consistent with the existing practices of the care continuum, patient feedbacks are handled by either the care provider or the UM.

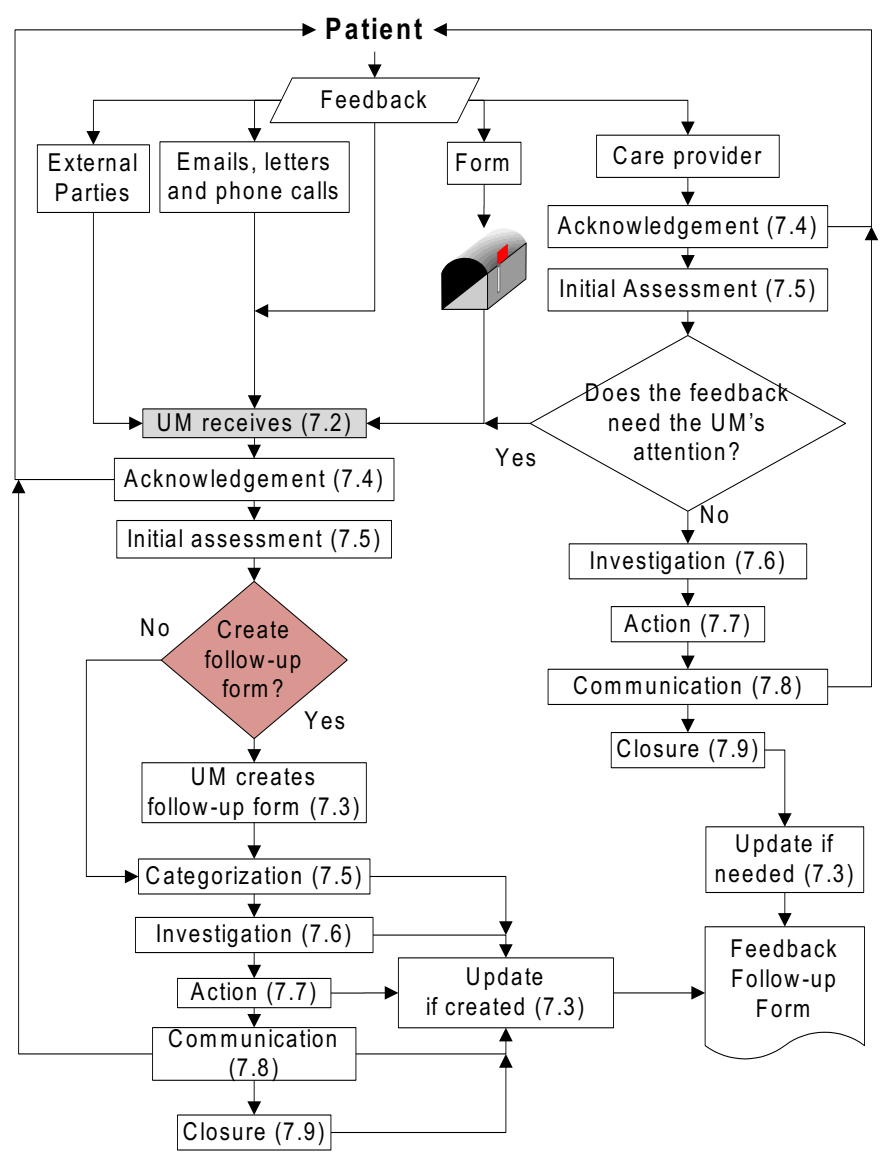

Figure 2. FHS Operations

When a care provider receives a feedback, he/she thanks the patient and assesses the issue. The care provider passes the feedback to the UM if it needs the UM's attention. Otherwise, the care provider investigates the issue, determines the action needed, performs the necessary action and communicates it to the patient.

Feedbacks from various sources eventually are conveyed to the UM, who tracks them till the closure. After receiving a feedback, the UM acknowledges the receipt, assesses it initially and determines the feedbacks for which subsequent activities should be documented and tracked in a "Feedback Follow-up Form". This is because it may not be possible for the UM, with the limited available time and resources, to record all the feedback-handling activities for all feedbacks. The procedure to determine whether or not the follow-up form is to be created is further detailed in Figure 3. 
Next, the UM categorizes the feedbacks. In the literature, there are examples of feedback categorizations (e.g., Allen, Creer and Leggitt, 2000; Baker, 2008; Montini, Noble and Stelfox, 2008). ISO 10002:2004 includes its own categories in the "Complaint follow-up form" (see Annex D). The central feedback-handling department already developed its own categorization that includes four "primary" categories: "access", "delivery of care", "environment" and "finance", with sub-categories for each primary category. The research participants stated that this list had been validated through its use over the preceding several years and that the hospital personnel are familiar with it. After considering the options, the central feedback-handling department's list was adapted in the follow-up form. For a different case, a customized list can be developed, or the existing one in ISO 10002:2004 can be used.

The UM investigates the feedback and determines and implements the required actions. Finally, the UM communicates to the patients the actions undertaken. Subsequently, the feedback is closed. If the patient is not satisfied and asks for further actions, the cycle is repeated. The follow-up form is updated with each activity.

The shaded diamond in Figure 2 is magnified in Figure 3, illustrating the criteria based on which feedbacks are selected for documenting their follow-up. ISO 10002:2004 does not specify any such procedure. This procedure is an additional component that should be useful for the feedback handing personnel. The criteria used in the procedure were developed and improved based on the comments from the research participants. More items can be included to the criteria based on the results from the implementation.

\begin{tabular}{|l|l|}
\hline UM creates follow-up form (7.3) & $\begin{array}{l}\text { 1. Is this an adverse event (e.g., wrong } \\
\text { medication was given to the patient)? }\end{array}$ \\
$\begin{array}{l}\text { 2. Has the patient submitted a feedback } \\
\text { form? }\end{array}$ \\
$\begin{array}{l}\text { 3. } \begin{array}{l}\text { Does the patient want to follow-up on } \\
\text { the feedback? }\end{array} \\
\text { 4. Was the matter resolved immediately? } \\
\text { time (e.g., more than one shift) to be } \\
\text { resolved? }\end{array}$ \\
\hline
\end{tabular}




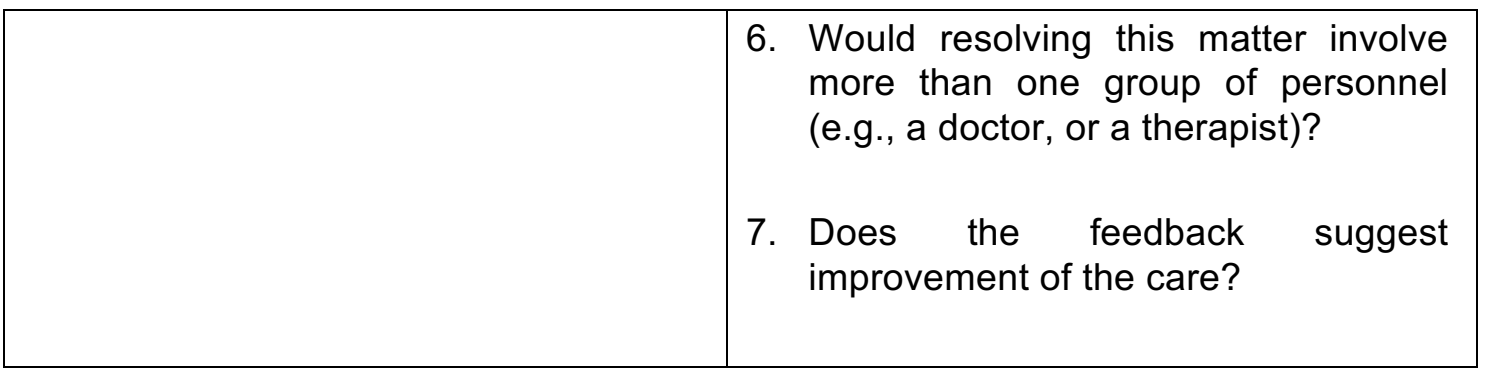

Figure 3. Decision procedure on creating a follow-up form

The "Feedback Follow-up Form" is adapted from the one provided by ISO 10002:2004, Annex D. Notable changes in the form from the original are:

- "Comment of the feedback receiver" is added, which should indicate the state of the patient and environment in which the feedback was conveyed.

- The "Problem category" is replaced by the adapted list.

- The 18-item checklist of "Complaint resolution” actions (ISO 10002: 2004, Annex D.6) is replaced by open-ended options to document "corrective", "preventive" and "improvement" actions, thereby simplifying the use of the form.

- To simplify and quicken the documentation of feedback assessment, the open-ended options for "Severity", “Complexity" and "Impact" (ISO 10002:2004, Annex D.5) were replaced by a close-ended score ranging from one to five.

\subsubsection{Maintenance and improvement of the FHS}

To measure the FHS performance in relation to the objectives (see 4.3.2), nine indicators were determined based on 10002:2004 Annex G.3.3 and ISO 10004:2012, sub-clause 7.3.2. Examples of indicators are:

a) Number of feedbacks received per category and sub-category;

b) Number of concerns resolved;

c) Number of corrective, preventive and improvement actions resulting from feedback analysis;

d) Wait times at various points of the continuum;

e) Number of received complaints regarding service coordination at the points of handing-off and discharge.

The ED and inpatients care aspects were considered in determining these indicators. For example, by studying the care flowchart, the specific point in the continuum where the waiting occurs can be identified (e.g., in the ED or at the handing-off to the inpatients). Waiting time at each of these points can be measured and monitored. Similarly, trends in the collected feedbacks can be determined, which can be related to patient satisfaction (ISO 10004:2012, sub-clause 7.3.2). By considering the entire care continuum as one 
system and monitoring the indicators across the continuum, intelligence can be obtained on patient satisfaction related to the received care. This may not be effectively done in the traditional feedback-handling because of its lack of focus on the continuum.

The feedback analysis can be validated (ISO 10004:2012, sub-clause 7.4.5) by comparing the consistency of the results against the existing surveys, reports and documents that are regularly generated by the hospital, as well as by the media. For instance, the public report on the HQCA's 2009 ED survey results includes the number of complaints received and any identifiable trends. The FHS performance indicators can be compared against this existing survey report.

The feedback analysis should be reported with recommendations on areas for improvement (ISO 10004:2012, sub-clause 7.4.6). The UMs of both the ED and inpatients can discuss the findings, as well as develop and implement the action plans together. The results and learning can be communicated to colleagues and the management (ISO 10004:2012, sub-clause 7.5). The collaborations among the UMs and the dissemination of the findings among colleagues demonstrate the coordinated effort without redundancy, which is a key benefit of IHC (Ouwens et al., 2005).

\section{Verification of the FHS}

To verify the usefulness and feasibility of the FHS, two personnel involved in feedback handling, one UM from inpatients care and three RNs (Registered Nurses) from the ED, were interviewed. Their responses are summarized in Table 1.

\begin{tabular}{|c|c|}
\hline Participants & Summary of findings \\
\hline $\begin{array}{l}\text { 1. Feedback- } \\
\text { handling experts }\end{array}$ & $\begin{array}{l}\text { - The FHS provides the unit-level care providers with a set of useful } \\
\text { tools for handling feedbacks } \\
\text { - The challenge of its implementation is to prove its value and benefit } \\
\text { to the care providers }\end{array}$ \\
\hline Inpatients care & $\begin{array}{l}\text { - Staff training specific to handling feedback should be conducted } \\
\text { - The feedback follow-up form can be helpful for a new UM to } \\
\text { anticipate what is expected from patients and how feedbacks are } \\
\text { traditionally dealt with }\end{array}$ \\
\hline ED & $\begin{array}{l}\text { - The staff should be convinced with answers to the following } \\
\text { questions about the FHS: } \\
\text { a) What is the evidence from the literature to show the need of it? } \\
\text { b) What difference would it make? How big would be its impact? } \\
\text { - The need for the level of technology use is limited, which is a } \\
\text { strength } \\
\text { It was suggested to omit the item related to adverse events from the } \\
\text { decision procedure (Figure } 3 \text {, "A"), because the hospital already has } \\
\text { defined procedures for such events }\end{array}$ \\
\hline
\end{tabular}


Table 1. Findings from verifications interviews

Based on the verification interviews, a lack of interest on the FHS was identified among the unit-level staff (RNs and UMs). Being occupied with many responsibilities, the staff may have viewed it as additional work. However, the interviewed feedback-handling experts were optimistic that the FHS should provide the unit-level staff with useful tools to help in handling feedbacks, something they already do as a part of their jobs.

Two RNs from the ED and a UM from the inpatients care were requested to evaluate the FHS by using the follow-up form for tracking real feedbacks. Response was only obtained from the UM, who documented the follow-up activities regarding three feedbacks. The findings validated the usefulness of the tracking process and helped in further improving the form. For instance, a new primary category named "other (specify)" is introduced in order to account for the feedbacks that do not fall under the existing options (i.e., "access", "delivery of care, "environment" and "finance"). Additionally, "billing" and "funding" as the secondary categories under "finance" were omitted, because they are not relevant to this particular care continuum. Overall, the follow-up process of the FHS worked satisfactorily, according to the UM. The form can be further improved by making it electronic, thereby more agile and efficient for the UM.

\section{Discussion}

In the FHS, new activities and items, which are not in ISO 10002:2004, were introduced. One example is the decision procedure (see Figures 2 and 3), which may save time for the unit-level personnel by helping them in making prompt selections of feedback for the follow-up documentation. The follow-up form includes an additional field titled "comment of the feedback receiver", which should help in capturing the state and tone of the patient at the point when the patient conveyed the feedback. This is an example of acknowledging the "moment of truth" (Osborne, 2004), as well as patient centeredness. Two additional notable changes made to the follow-up form are: (1) a different categorization of feedbacks is introduced and (2) the long list of complaint resolution actions from Annex D.6 of the standard (page 16) is replaced by the open-ended "corrective", "preventive" and "improvement actions". These actions were intended to make the recording of the maintenance activities less cumbersome for the already busy UMs.

The gaps listed in section 4.2 of this paper are all addressed in the FHS. The FHS provides an organized system for the "unit-level" handling of feedbacks (4.2.a) and includes orally- 
conveyed feedbacks (4.2.b). The gap regarding the use of the feedback (4.2.c) can be closed by integrating the efforts of the UMs from both care stages. Guiding all feedbacks from various sources and work groups to the UM and keeping the UM responsible for the tracking should lead to effective and consistent handling of feedbacks (4.2.d). Having the UMs of the two stages discuss and share feedbacks left at their own stages should result in better coordination and organization of the follow-up activities and less probability of lost feedbacks between stages (4.2.e and f). Therefore, the FHS can provide "a broad overview" (Deffenbaug, 1994) of patient feedbacks on the care, as well as reduce fragmentation and improve the continuity and coordination (Ouwens et al., 2005), all of which are key benefits of IHC and are included in the FHS objectives (see 4.3.2).

Successful implementation of the FHS will require commitment from the care providers and support staff, who should be made aware of the significance of patient feedback and trained on its proper handling. Presenting evidence to the staff on how their recommendations are implemented should make them feel more involved and dedicated to feedback handling. If the FHS seems to increase the workload of the UMs, volunteers and nursing students can be recruited for documenting the follow-up activities under the supervision of the UM.

\section{Conclusions}

The implementation of the FHS can assist in closing the identified gaps in the existing feedback-handling activities of the hospital. Overall, a set of standardized processes are provided that should help health care personnel in handling feedbacks efficiently. By following the steps suggested in the methodology, the FHS can be applied in other care continua (e.g., maternity, chronic disease management and primary care), and can include other groups of personnel (such as doctors and therapists). The FHS can be implemented at the unit-level, where the interviewed experts suggested that it should be useful, even without the presence of an overarching feedback-handling body. This demonstrates the flexibility of ISO 10002:2004. Keeping the UMs responsible for overseeing the feedback follow-up processes is not a requirement of the standard, rather an example of having one responsible person from each stage of the care continuum. This should help in maintaining the coordination and flow of the follow-up activities between stages.

The paper illustrated that ISO 10002:2004 can be useful in IHC. The integrated use of ISO 10002:2004 and ISO 10004:2012 in health care is a novel approach, exemplifying how the maintenance and improvement activities in Clause 8 of ISO 10002:2004 can be 
"augmented" by sub-clauses 7.3 to 7.6 and Annexes D and E of ISO 10004:2012. To our knowledge, examples of such integrated applications have not yet been reported.

The FHS demonstrated how "patient centeredness", a key principle of IHC (e.g., Friedman et al., 2001; O'Malley et al., 2008), can be implemented by applying the ISO 10002:2004 and ISO 10004:2012, two international standards focused on customers. The FHS also showed how the IHC principle regarding the "continuum of care" (e.g., Friedman et al., 2001; Suter et al., 2009) can be maintainedby the application of ISO 10002:2004, which should help integrate the handling of feedbacks at various stages of care that a patient experiences. Moreover, the literature still lacks examples of a comprehensive framework specific to IHC for handling both solicited (e.g., through surveys and focused groups) and unsolicited (e.g., through feedback forms and cards) feedbacks. This work depicts the function of such a framework.

The implementation of the FHS was beyond the constraints of this research. Physicians and support staff (such as technicians and dietary) were not involved in the FHS design and verification interviews. Their inputs may have been useful in further refining the FHS.

The results from this paper contribute to the application of the ISO 10000 standards in health care, which still has not seen significant exploration. For example, establishment and implementation of a customer satisfaction promise based on ISO 10001:2007 isreported in Authors (2013) and (2014a). The handling of solicited feedback based on ISO 10004:2012 is discussed in Authors (2014b).

Using this paper as the baseline, it should be interesting to explore a pilot implementation by involving several ED and inpatients care units to further test the FHS's usefulness and feasibility. The composition and usefulness of the decision procedure presented in this paper (Figure 3) can be further investigated when the FHS is actually implemented. The level of patient satisfaction with the FHS can be determined by conducting patient interviews or a survey, as suggested by ISO 10002:2004 (sub-clause 8.3). Such a survey can be designed by applying ISO 10004:2012 to further explore the integrated use of the two standards. The effectiveness of the FHS can be evaluated by implementing the ISO 19011:2012 auditing standard. 


\section{REFERENCES}

Allen, L.W., Creer, E. and Leggitt, M. (2000). Developing a patient complaint tracking system to improve performance. Joint Commission Journal on Quality Improvement, 26 (4), 217-226.

Anderson, K., Allan, D. and Finucane, P. (2000). Complaints concerning the hospital care of elderly patients: a 12-month study of one hospital's experience. Age and Ageing, 29, 409-412.

Ang, L. and Buttle, F. (2012). Complaints-handling processes and organisational benefits: an ISO 10002-based investigation. Journal of Marketing Management, 28, (9-10), 10211042

Armitage, G.D., Suter, E., Oelke, N.D. and Adair, C.E. (2009). Health systems integration: state of the evidence. International Journal of Integrated Care, 9 (June), 1 11 .

Khan, M.A.R. and Karapetrovic, S. (2014). Establishing an ISO 10001-based promise in inpatients care. International Journal of Health Care Quality Assurance (Accepted and awaiting publication).

Khan, M.A.R. and Karapetrovic, S. (2013). Implementing an ISO 10001-based promise in inpatients care. International Journal for Quality Research, 7 (3), 335-346.

Khan, M.A.R. and Karapetrovic, S. (2014). Patient satisfaction measurement along a continuum of care. Submitted for review.

Baker, S.K. and Bank, L. (2008). "I'm sorry to hear that...". Real life responses to patients' 101 most common complaints about health care. Fire Starter Publishing, Gulf Breeze, FL.

Capital Health. (2008). Project description: customer satisfaction for integration initiatives. Internal document. Alberta Health Services (from 2009 to current).

Coyle, J. and Williams, B. (1999). Seeing the wood for the trees: defining the forgotten concept of patient dissatisfaction in the light of patient satisfaction research. International Journal of Health Care Quality Assurance Incorporating Leadership in Health Services, $12,(6-7), \mathrm{i}-\mathrm{ix}$.

Davis, P., Lay-Yee, R. and Briant, R. (2008). Patient dissatisfaction recorded in hospital notes in New Zealand: their occurrence and pattern. New Zealand Medical Journal, 121 (1273), 51-59.

Deffenbaugh, J.L. (1994). Health-care continuum. Health Manpower Management, 20(3), 37-39.

Eccles, G. and Durand, P. (1998). Complaining customers, service recovery and continuous improvement. Managing Service Quality, 8 (1), 68-71. 
Fernandez, E., Karapetrovic, S. and Brooks, P.M. (2010). ISO 10002 in health care: update on a case study. The 14th International Conference on ISO 9000 \& TQM, University of Scranton, Pennsylvenia, USA, 5-7 ${ }^{\text {th }}$ April 2010.

Friedman, L., Goes, J., Coddington, D.C., Linenkugel, N. and et al. (2001). Why integrated health networks have failed / Commentaries / Reply. Frontiers of Health Services Management, 17 (4), 3-54.

Gingold, S.R. (2011). The value proposition of patient feedback. Journal of Medical Practice Management, 27 (1), 7-9.

Honarkhah, M. (2010). An application of ISO 10001 and ISO 10002 in engineering courses. The 14th International Conference on ISO 9000 and TQM, University of Scranton, Pennsylvenia, USA, 5-7 ${ }^{\text {th }}$ April 2010.

HQCA (2010).Satisfaction and experience with health care services: a survey of Albertans, Health Quality Council of Alberta. Available at http://www.hqca.ca/assets/pdf/Surveys/HQCA_SE_Technical_Report_2010.pdf/ (accessed 7 February 2014).

HQCA (2009). Urban and regional emergency department patient experience report", Health Quality Council of Alberta. Available at http://www.hqca.ca/assets/pdf/ ED\%20January\%202010/Urban_and_Regional_Emergency_Department_2009_FINAL. pdf (accessed 7 February 2014).

HQCA (2007). Patient concerns/complaints resolution provincial framework, Health Quality Council of Alberta. Available at http://www.hqca.ca/phpBB2/files/ hqca_concerns_framework_2007_157.pdf (accessed 7 February 2014).

Hsieh, S.Y., Thomas, D. and Rotem, A. (2005). The organisational response to patient complaints: a case study in Taiwan. International Journal of Health Care Quality Assurance Incorporating Leadership in Health Services, 18 (4-5), 308-320.

Hughes, S. and Karapetrovic, S. (2006). ISO 10002 complaints handling system: a study. International Journal of Quality\& Reliability Management, 23 (9), 1158-1175.

ISO 10002 (2004). Quality management - Customer satisfaction - Guidelines for complaints handling in organizations, International Organization for Standardization, Geneva, Switzerland.

ISO 10004 (2012). Quality management - Customer satisfaction - Guidelines for monitoring and measuring, International Organization for Standardization, Geneva, Switzerland.

Karapetrovic, S. (2010). Teaching with ISO 10001 and ISO 10002. Joint International IGIP-SEFI Annual Conference in Trnava, Slovakia, 19-22 September 2010.

Kerber, K.J., de Graft-Johnson, J.E., Bhutta, Z.A., Okong, P., Starrs, A. and Lawn, J.E. (2007). Continuum of care for maternal, newborn, and child health: from slogan to service delivery. Lancet, 370 (9595), 1358-1369. 
Kline, T.J., Willness, C. and Ghali, W.A. (2008). Predicting patient complaints in hospital settings. Quality \& Safety in Health Care, 17 (5), 346-350.

Kress, G. and Silversin, J. (1983). Patient feedback project provides real measure of patient satisfaction. Dental Economics, 73 (4), 72-73.

Lamb, G.S. (1997). Outcomes across the care continuum. Medical Care, 35 (11)NS10614.

Levine, A.S., Plume, S.K. and Nelson, E.C. (1997). Transforming patient feedback into strategic action plans. Quality Management in Health Care, 5 (3), 28-40.

Miller, M.J. and Ferrin, D.M. (2005). The application of simulation methodology in a hospital's six sigma project. Proceedings of the 37th Conference on Winter Simulation, Orlando, Florida, USA 2007, IEEE Xplore, 2016-2019.

Montini, T., Noble, A.A. and Stelfox, H.T. (2008). Content analysis of patient complaints. International Journal for Quality in Health Care, 20 (6), 412-420.

Mulcahy, L. and Tritter, J.Q. (1998). Pathways, pyramids and icebergs? Mapping the links between dissatisfaction and complaints. Sociology of Health \& Illness, 20 (6), 825847.

Mur-Veeman, I., Hardy, B., Steenbergen, M. and Wistow, G. (2003). Development of integrated care in England and the Netherlands: managing across public-private boundaries. Health Policy, 65 (3), 227-241.

NHS (2003). Reforming the NHS complaints procedure patient focus and public involvement. Available athttp://www.scotland.gov.uk/Resource/Doc/47032/ 0013908.pdf (accessed 7 February 2014).

Nordlund, Y.G. and Edgren, L. (1999). Patient complaint systems in health care: a comparative study between the Netherlands and Sweden. European Journal of Health Law, 6 (2), 133-154.

O'Malley, P.J., Brown, K. and Krug, S.E. (2008). Patient-and family-centered care of children in the emergency department. Pediatrics, 122(2), e511-521.

Osborne, L. (2004). Resolving patient complaints: a step-by-step guide to effective service recovery. 2nd Edition, Jones and Bartlett Publishers, Sudbury, MA.

Ouwens, M., Wollersheim, H., Hermens, R., Hulscher, M. and Grol, R. (2005). Integrated care programmes for chronically ill patients: a review of systematic reviews. International Journal for Quality in Health Care, 17(2), 141-146.

Saravanan, B., Ranganathan, E. and Jenkinson, L.R. (2007). Lessons learnt from complaints by surgical patients", Clinical Governance: An International Journal, 12 (3), 155-158. 
Seelos, L. and Adamson, C. (1994). Redefining NHS complaint handling - The real challenge. International Journal of Health Care Quality Assurance, 7 (6), 26-31.

Smith, A.E. and Swinehart, K.D. (2001). Integrated systems design for customer focused health care performance measurement: a strategic service unit approach. International Journal of Health Care Quality Assurance, 14 (1), 21-28.

Stichler, J.F. and Schumacher, L. (2003). A gift of customer complaints. Marketing Health Services, 23 (4),14-15.

Suter, E., Oelke, N.D., Adair, C.E. and Armitage, G.D. (2009). Ten key principles for successful health systems integration. Healthcare Quarterly, 13, 16-23.

Thomas, P. and While, A. (2007). Should nurses be leaders of integrated health care? Journal of Nursing Management, 15 (6), 643-648.

Zairi, M. (2000). Managing customer dissatisfaction through effective complaints management systems. The TQM Magazine, 12 (5), 331-337. 